九州大学学術情報リポジトリ

Kyushu University Institutional Repository

\title{
An Improved Impeller for Aerated Agitation
}

Fujio, Yusaku

Laboratory of Biochemical Engineering, Faculty of Agriculture, Kyushu University

Sambuichi, Masao

Laboratory of Biochemical Engineering, Faculty of Agriculture, Kyushu University

Ueda, Se inosuke

Laboratory of Biochemical Engineering, Faculty of Agriculture, Kyushu University

https://doi.org/10.5109/22854

出版情報 : 九州大学大学院農学研究院紀要. 18 (3)，pp. 169-180，1974-06. Kyushu University バージョン：

権利関係 : 


\title{
An Improved Impeller for Aerated Agitation
}

\author{
Yusaku Fujio, Masao Sambuichi and Seinosuke Ueda \\ Laboratory of Biochemical Engineering, Faculty of Agriculture, \\ Kyushu University, Fukuoka
}

(Received February 18, 1974

\begin{abstract}
An improved type of impeller has been designed to obtain higher efficiency under the conditions of lower stirrer speed and lower gassing rate. Experiments and analyses were carried out for the absorption system of oxygen from air into water. From the experimental results, this type of impeller was found to be effective and a correlation was found between the volumetric coefficient for oxygen in the air and aeration number. For aerated agitation, it is considered that the width of impeller acts an important factor for mass transfer on agitated vessel with aeration. Some quantitative relationships were obtained between width of impeller and dimensionless groups involving a modified aeration number.
\end{abstract}

\section{INTRODUCTION}

In the classical studies on agitated vessel with aeration, there are wellknown papers by Cooper et al. (1944) and Ohyama et al. (1955). It has been shown in these papers that there are quantitative correlations between aeration rate and power consumption. From these correlations, data have been obtained which form the basis of scale-up and of design of agitated vessel with aeration. From another view point, for aerated vessels, investigation on mass trannsfer from bubbles to liquid using aerated vessel has shown that dependence exists between the volumetric coefficient and operational variables involving power consumption (Steel et al. 1958). Calderbank (1958) has measured interfacial area between gas and liquid by a physical method, and has shown that interfacial area depends on physical properties of gas and liquid and on operational conditions. A small number of standard impellers have been used for agitation in the experiment related with interfacial area or other studies, and have usually been similar to those in actual equipments.

On the other hand, in order to stimulate gas absorption or reaction between liquid and gas phase in agitated vessel with aeration, it is desirable that the aeration system possesses a high numerical value of volumetric coefficient. A large numerical value of volumetric coefficient can often be obtained at a higher rotational rate of impeller and at higher rate of aeration. But, because of foaming and other mechanical problems of equipment, these conditions are not suitable for operation. For these reasons, equipment for aerated vessel should, if possible, have a large volumetric coefficient under the operational conditions of low aeration rate and low rotational rate. For these purpose, an improved 
impeller with a wide blade has been designed like a flat turbine. The improved impeller has been studied in relation to volumetric coefficient at different rotational speeds and rates of aeration,

The effects of width of impeller blade on the volumetric coefficient and aeration number have been studied quantitatively under the conditions of aeration. Other investigations under these conditions have apparently not been reported previousay.

\section{EXPERIMENTAL APPARATUS}

Fig. 1 shows a schematic view of the experimental apparatus and the system for mesuring dissolved oxygen concentration. The vessel was made of pyrex, and four baffles made of stainless steel were fixed in the vessel. A ring type of nozzle for gassing was made of $10 \mathrm{~mm} \phi$ stainless steel pipe, and it was $60 \mathrm{~mm} \phi$ in diameter with 10 small holes $(1.6 \mathrm{~mm} \phi)$ in same pitch. There were two gassing systems for air from compressor and for nitrogen gas from a nitrogen cylinder. Air was used for oxygen transfer from air to liquid and the flow rate of air was measurred accurately by an air flow meter. Nitrogen gas was used for desorption of dissolved oxygen in the water. For measurement of dissolved oxygen concentration in water, an oxygen analyzer (BeckmanToshiba type 777) was used. A flow system was used for measuring the dissolved oxygen concentration, the liquid in the vessel being circulated at the top of oxygen sensor by using a small pipe (I. D. $3 \mathrm{~mm} \phi$ ) and a peristalitic pump. The measured value of dissolved oxygen concentration was recorded by a recorder (Yokogawa, type 3060). To hold a constant temparature, the vessel was fixed in a water bath with a temperature controlling system.

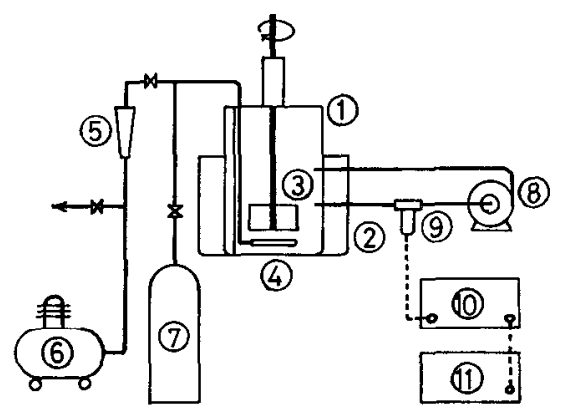

Fig. 1. Flow sheet of experimental apparatus.

$\begin{array}{llrl}1 & \text { Vessel } & 7 & \mathrm{~N}_{2} \text { Bomb } \\ 2 & \text { Water bath } & 8 & \text { Pump } \\ 3 & \text { Impeller } & 9 & \text { Oxygen sensor } \\ 4 & \text { Nozzle } & 10 & \text { Oxygen analyzer } \\ 5 & \text { Flow meter } & 11 & \text { Recorder } \\ 6 & \text { Air compressor } & & \end{array}$

Fig. 2(a) shows the dimensions and fitting positions of the vessel, impeller, bathes and ring type nozzle. Each of impellers used was fitted at a constant 


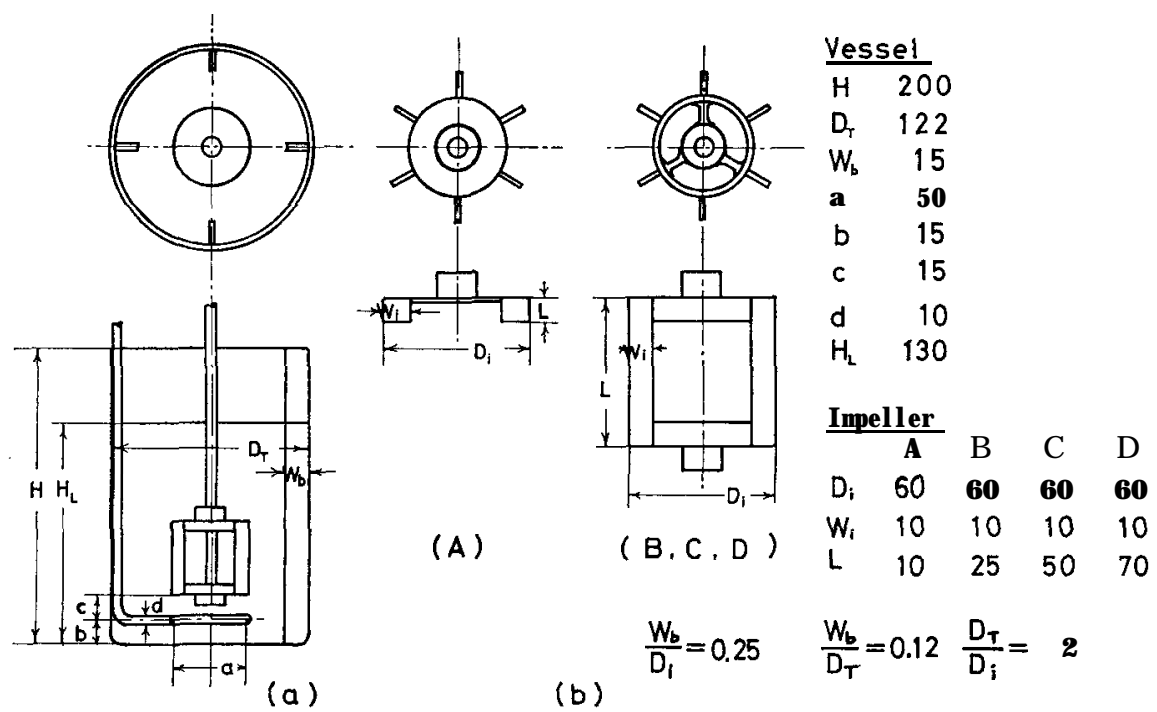

Fig. 2. Vessel used and improved impellers.

distance from lower edge of impeller blade to bottom of vessel. Fig. 2(b) shows the impellers used in these experiments. Type $\mathrm{A}$ is a standard impeller with a six bladed flat turbine, and this impeller is used as a standard to compare with others. Type B, C and D are improved six bladed impellers for aerated agitation, and $\mathrm{B}, \mathrm{C}$ and $\mathrm{D}$ differ from each other in width of blade. The dimension ratios of the impellers used are shown in Fig. 2(b).

\section{EXPERIMENTAL PROCEDURE AND MESUREMENTS OF $\boldsymbol{k}_{L} \boldsymbol{a}$}

The liquid used for experiments was $1.5 l$ of water, since the depth in the vessel without aeration was nearly equal to the diameter of the vessel. The rotational rate of the impeller was measured by means of a hand tachometer. The volumetric coefficients of agitated vessel with aeration were measured by the oxygen transfer rate from aerated air to water. Dissolved oxygen concentration in the water was measured by means of an oxygen analyzer on the polarographic principle. A flow system used for measurement of dissolved oxygen concentration because of sensitivity and accuracy. The liner velocity of circulating water under the measuring conditions was $2.6 \mathrm{~m} / \mathrm{sec}$ at the top of the oxygen sensor. A velocity of $2.6 \mathrm{~m} / \mathrm{sec}$ was chosen for the measuring conditions after preliminary experiments. It was confirmed by the same preliminary experiments that the measurements of dissolved oxygen concentration were not affected by the existence of bubbles. Since $\boldsymbol{k}_{L} \boldsymbol{a}$ depends on temperature, a constant temperature of $30^{\circ} \mathrm{C}$ was held throughout the experiments.

The $k_{L} a$ 's values were obtained by the following procedure:

1) adjust the experimental system at required rotational rate and aeration rate.

2) stop the aeration by a magnetic valve.

3) start the nitrogen gassing, instead of aeration. until a zero value of dissolved 


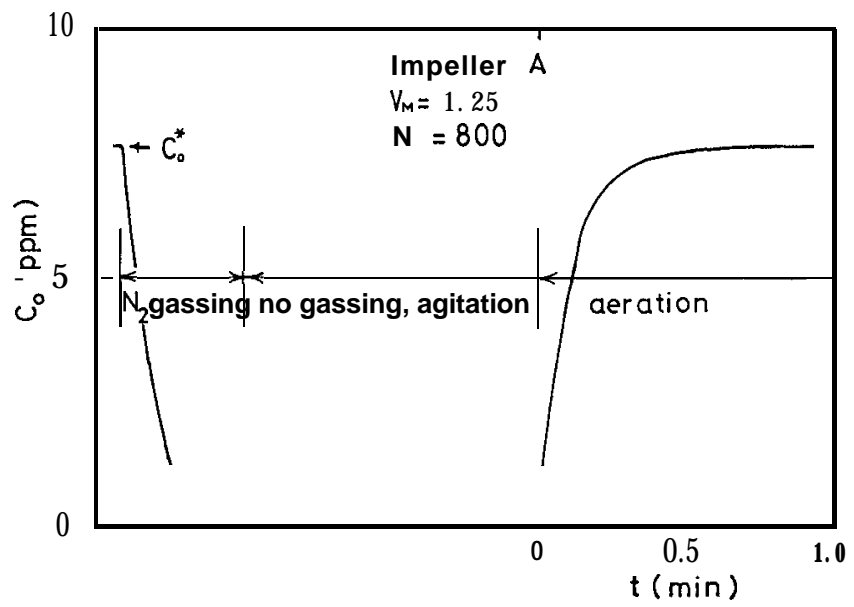

Fig. 3. Time course of dissolved oxygen change according to measuring procedures of volumetric coefficient.

oxygen concentration in the water was reached.

4) stop the nitrogen gassing and agitation, and displace the remaining nitrogen gas above the watar level by air.

5) start the agitation and aeration under the conditions required, measuring and recording the increasing value of dissolved oxygen concentration in the water.

Fig. 3 shows an example of the time course of dissolved oxygen concentration using above procedures. Numerical values of $k_{L} a$ could be calculated from this time history, as follows.

$$
\begin{aligned}
& \frac{\mathrm{d} C_{0}}{\mathrm{~d} t}=k_{L} a\left(C_{0} *-C_{0}\right) \\
& \ln \left(\frac{C_{0} *-C_{01}}{C_{0} *-C_{02}}\right)=k_{L} a\left(t_{1}-t_{2}\right)
\end{aligned}
$$

Numerical value of $k_{L} a$ were calculated using various combinations among aeration rates, $0.25,0.50,0.75,1.00$ and $1.25 \mathrm{vvm}$ and impeller rotational rates of 300 , 400, 500, 600, 700 and $800 \mathrm{rpm}$. These experiments were carried out with impellers of types $\mathrm{A}, \mathrm{B}, \mathrm{C}$ and $\mathrm{D}$ respectively.

\section{EXPERIMENTAL RESULTS AND DISCUSSION}

\section{1) Effects of width of impeller blade on volumetric coefficient}

In agitated vessel without aeration, Kamei et al. (1949) have studied the effects of power consumption on width of blade of flat turbines. Recently, studying heat transfer using agitated vessels, Mizushina et al. (1971) reported the effects of width of blade. From these results, the width of impeller blade should affact the volumetric coefficient of agitated vessel with aeration.

The $k_{L} a$ 's numerical values measured in the experiments are tabulated in 
Table 1. Obtained $k_{\mathrm{L}} a$.

\begin{tabular}{|c|c|c|c|c|c|}
\hline$N \backslash V_{M}$ & 0.25 & 0.50 & 0.75 & 1.00 & 1.25 \\
\hline \multicolumn{6}{|c|}{ Impeller A. $D_{i} / L=4.0$} \\
\hline $\begin{array}{l}300 \\
400 \\
500 \\
600 \\
700 \\
800 \\
\end{array}$ & $\begin{array}{l}0.25 \\
0.50 \\
1.10 \\
1.83 \\
2.48 \\
3.12 \\
\end{array}$ & $\begin{array}{l}0.43 \\
0.87 \\
1.62 \\
2.57 \\
3.37 \\
4.17 \\
\end{array}$ & $\begin{array}{l}0.50 \\
1.05 \\
1.88 \\
3.03 \\
3.80 \\
4.97 \\
\end{array}$ & $\begin{array}{l}0.67 \\
1.17 \\
2.08 \\
3.25 \\
4.25 \\
5.50\end{array}$ & $\begin{array}{l}0.77 \\
1.23 \\
2.17 \\
3.52 \\
4.62 \\
5.55\end{array}$ \\
\hline \multicolumn{6}{|c|}{ Impeller $\mathrm{B}, D_{i} / L=2.40$} \\
\hline $\begin{array}{l}300 \\
400 \\
500 \\
600 \\
700 \\
800\end{array}$ & $\begin{array}{l}0.27 \\
0.72 \\
1.57 \\
2.48 \\
3.30 \\
4.42\end{array}$ & $\begin{array}{l}0.42 \\
1.05 \\
2.18 \\
3.25 \\
4.13 \\
5.45\end{array}$ & $\begin{array}{l}0.52 \\
1.28 \\
2.43 \\
3.63 \\
4.68 \\
5.83\end{array}$ & $\begin{array}{l}0.60 \\
1.40 \\
2.83 \\
3.77 \\
5.08 \\
6.18\end{array}$ & $\begin{array}{l}0,67 \\
1.57 \\
2.78 \\
4.00 \\
5.40 \\
6.60\end{array}$ \\
\hline \multicolumn{6}{|c|}{ Impeller $\mathrm{C}, D_{l} / L=1.20$} \\
\hline $\begin{array}{l}300 \\
400 \\
500 \\
600 \\
700 \\
800\end{array}$ & $\begin{array}{l}0.63 \\
1.45 \\
2.62 \\
3.85 \\
5.08 \\
6.75\end{array}$ & $\begin{array}{l}0.78 \\
1.65 \\
3.08 \\
4.62 \\
5.55 \\
6.90\end{array}$ & $\begin{array}{l}0.90 \\
1.82 \\
3.37 \\
4.92 \\
5.83 \\
6.98\end{array}$ & $\begin{array}{l}0.93 \\
1.92 \\
3.57 \\
5.32 \\
6.32 \\
7.50\end{array}$ & $\begin{array}{l}1.02 \\
2.10 \\
3.68 \\
5.35 \\
6.1 \mathrm{la} \\
8.00\end{array}$ \\
\hline \multicolumn{6}{|c|}{ Impeller $\mathrm{D}, D_{i} / L=0.86$} \\
\hline $\begin{array}{l}300 \\
400 \\
500 \\
600 \\
700 \\
800\end{array}$ & $\begin{array}{l}0.90 \\
1.97 \\
3.17 \\
4.78 \\
6.32 \\
8.00\end{array}$ & $\begin{array}{l}1.03 \\
2.18 \\
3.80 \\
5.22 \\
6.52 \\
7.70\end{array}$ & $\begin{array}{l}1.02 \\
2.38 \\
4.00 \\
5.27 \\
6.67 \\
\text { a. } 12\end{array}$ & $\begin{array}{l}1.05 \\
2.42 \\
4.17 \\
5.13 \\
6.67 \\
7.27\end{array}$ & $\begin{array}{l}1.07 \\
2.52 \\
4.45 \\
5.83 \\
6.98 \\
\text { a. } 12\end{array}$ \\
\hline
\end{tabular}

Table 1. For the purpose of comparison of $k_{L} a$ obtained by impellers A, B, C and $\mathrm{D}$, respectively the ratios of each $\boldsymbol{k}_{L} a$ to that of $\mathrm{A}$ were determined at the several aeration rates and it is shown in Fig. 4. The rotational rate was used as the parameter and the higher value of the ratio of each $k_{L} a$ was found at the lower aeration rate. Moreover, the wider blade of impeller has a tendency to induce higher values of this ratio. The same results were found with the rotational rate used as the parameter. Effects of the ratios of width of blade of flat turbine A to that of imroved impellers B, C and D, on volumetric coefficients, are shown in Fig. 5 in which rotational rate of the impeller are used as the parameter. From Fig. 5, the width of blade was found to affect highly the volumetric coefficient at the lower aeration rates and the lower rotational rates. From these results, improved impeller seems to be most suitable for the agitated vessel with aeration. From the viewpoint of mass transfer operations from gas to liquid, the improved impeller could be confirmed as more useful compared with the flat turbine. For example, Fig. 6 shows the effects of the ratios of the impeller's diameter, to width of blade, on volumetric coefficients. From these results, the higher numerical value of $k_{L} a$ was found at the smaller value of $\left(D_{i} / L\right)$, and the slopes shown in Fig. 6 were nearly equal to the various rotational rates of impeller. The same results were obtained for aeration rate 


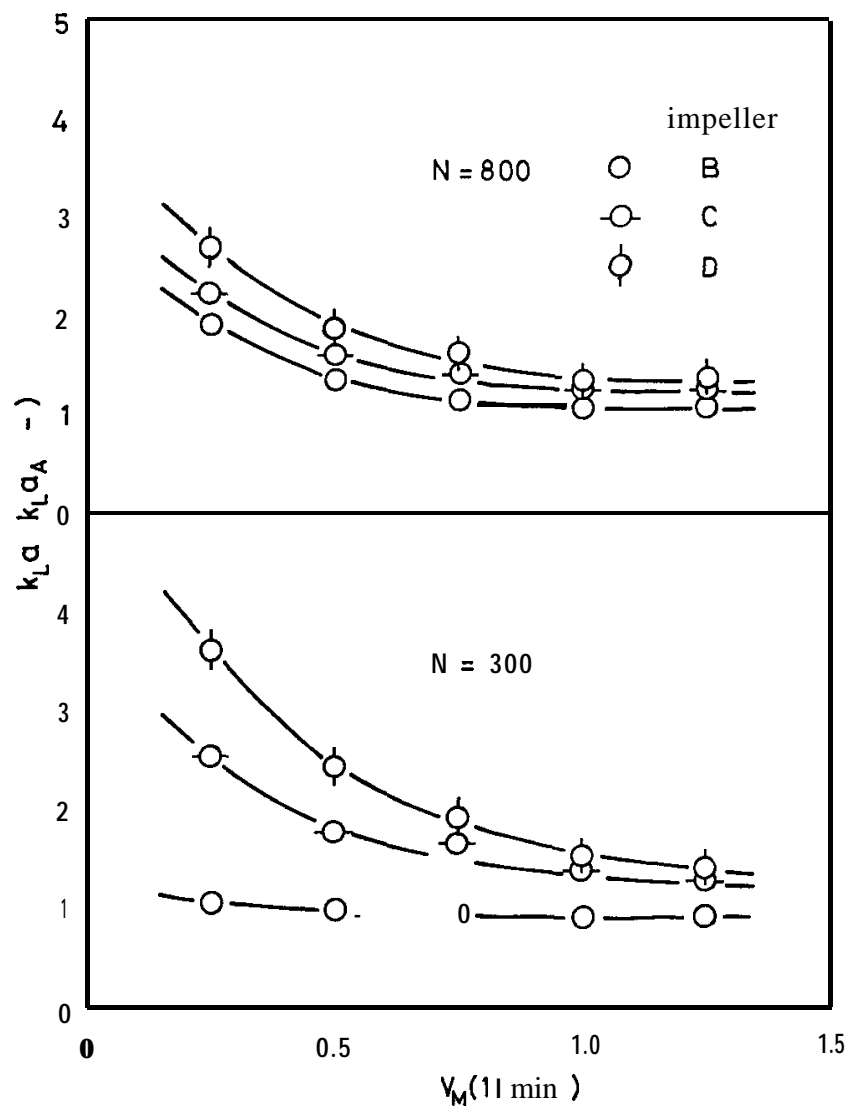

Fig. 4. Effect of aeration rate on $k_{L} a, k_{L} a_{\mathrm{A}}$ means $k_{L} a$ for standard flat turbine, $\mathrm{A}$.

under the condtions of the constant rotational rate. Two examples on 400 and $700 \mathrm{rpm}$ are shown in Fig. 7. A dependence of the slopes on the aeration rate was recognized in Fig. 7, and the same slopes were found at the same aeration rate. From the results shown in Figs. 6 and 7, it was confirmed that there was a quantitative relationship between volumetric coefficients and width of impeller blade.

\section{2) Correlation between $\boldsymbol{k}_{L} \boldsymbol{a}$ and modified aeration number}

The aeration number defined by Ohyama et al. (1955) has been concluded to be a factor in bubble dissipation in aerated agitation system. According to Calderbank (1958), the interfacial area between gas bubbles and liquid was in proportion to logarithms of rotational rate, under the condition of Reynolds number more than $2 \times 10^{4}$. It would be expected that the diameters of formed bubbles would decrease in proportion to intensity of agitation. For mass transfer from gas to lipuid in agitated vessel with aeration, effect of interfacial area may be obtained linearly from $k_{L} a$. Thus logarithmic values of $k_{L} a$ must be in proportion to the aeration number, $N_{A}$. Fig. 8 shows the relationship between $k_{L} a$ and $N_{A}$ obtained from these experiments in which the aeration rates were 


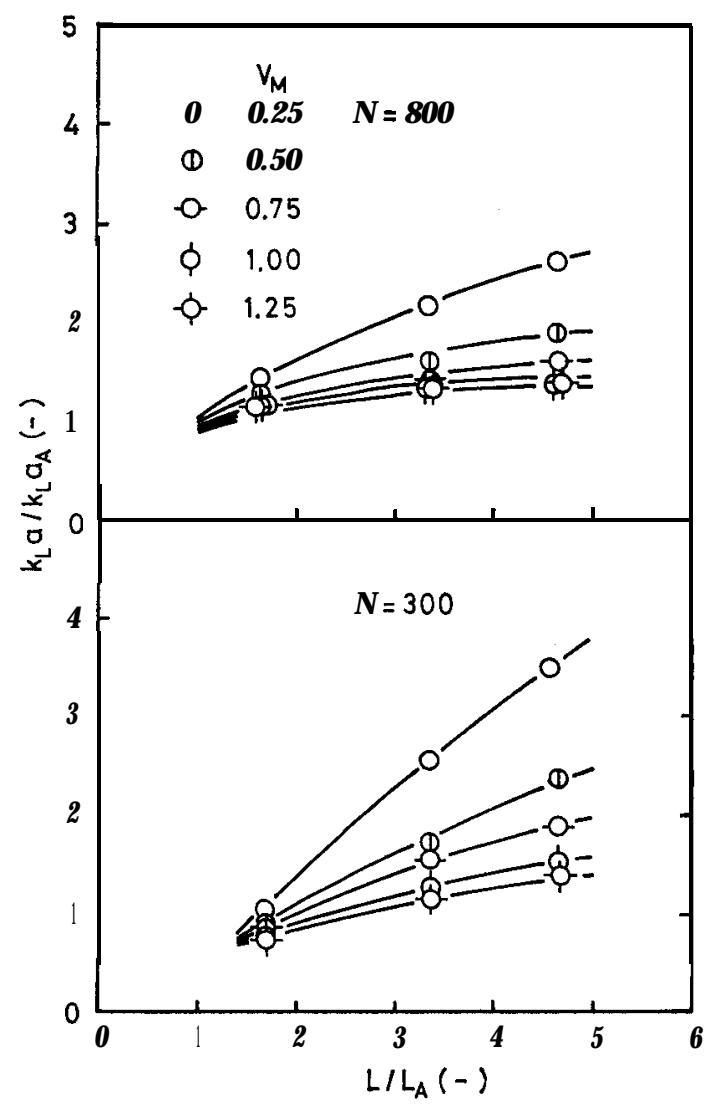

Fig. 5. Effect of width of blade of impellers on $k_{L} a$.

used as parameter. The same results as shown in Fig. 8 cuold be obtained in the case of improved impellers B, C and D respectively. From these correlations it was confirmed that the volumetric coefficient $k_{L} a$ is related to the aeration number, $N_{A}$. On the other hand, power consumption per unit volume of liquid has been related to absorption number by Cooper et al. (1944). In the present paper, $\left(k_{L} a / V_{M}\right)$ was given as the absorption number, when $\left(k_{L} a / V_{M}\right)$ is an important factor for an agitated vessel with aeration in the case of mass transfer from gas to liquid. It may be considered that $\left(k_{L} a / V_{\mu}\right)$ is a function of volumetric flow rate of gas, rotational rate of impeller and geometrical shapes of impeller and vessel, i. e., $\left(D_{i} / L\right), N_{A}$ and $V^{*}$ are related to $\left(k_{L} a / V_{M}\right)$. Analysis was carried out for Eq. (2).

$$
\left(\frac{k_{L} a}{V_{M}}\right) \propto \alpha\left(\frac{D_{i}}{L}\right)^{\mathrm{a}} \cdot\left(N_{A}\right)^{\mathrm{b}} \cdot\left(V^{*}\right)^{\mathrm{c}}
$$

Where, $V^{*}$ is defined as the ratio of each volumetric flow rate of air to unit volumetric flow rate. It may be useful that $q_{A}$, gas flow rate, involved in the term of $N_{A}$, was divided by $V^{*}$, since the results can then be compared on the same basis, where $\left(N_{A} / V^{*}\right)$ is defined as a modified aeration number instead of 


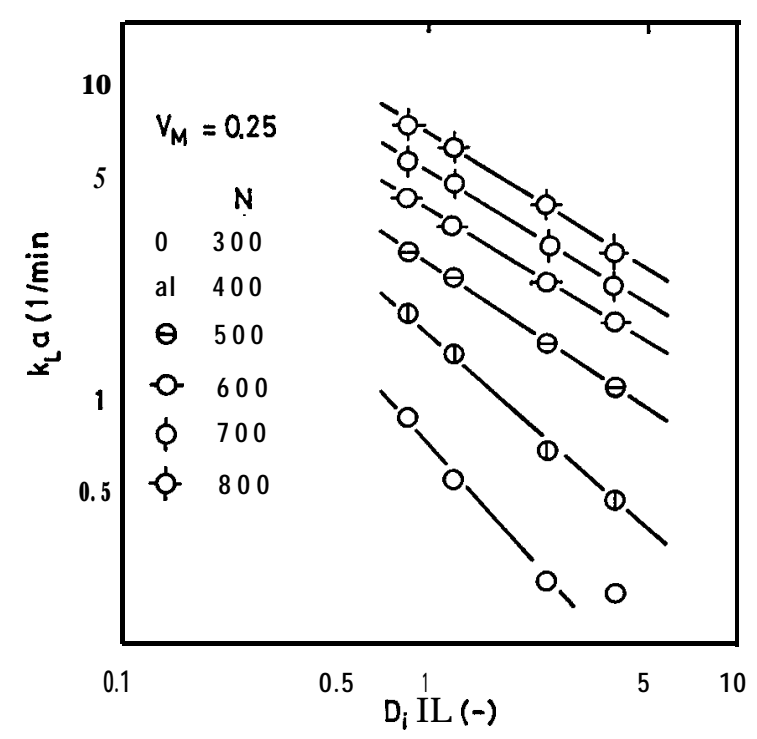

Fig. 6. Correlations $D_{i} / L$ and $k_{L} a$ under the condition of $V_{\mu}=0.25$.

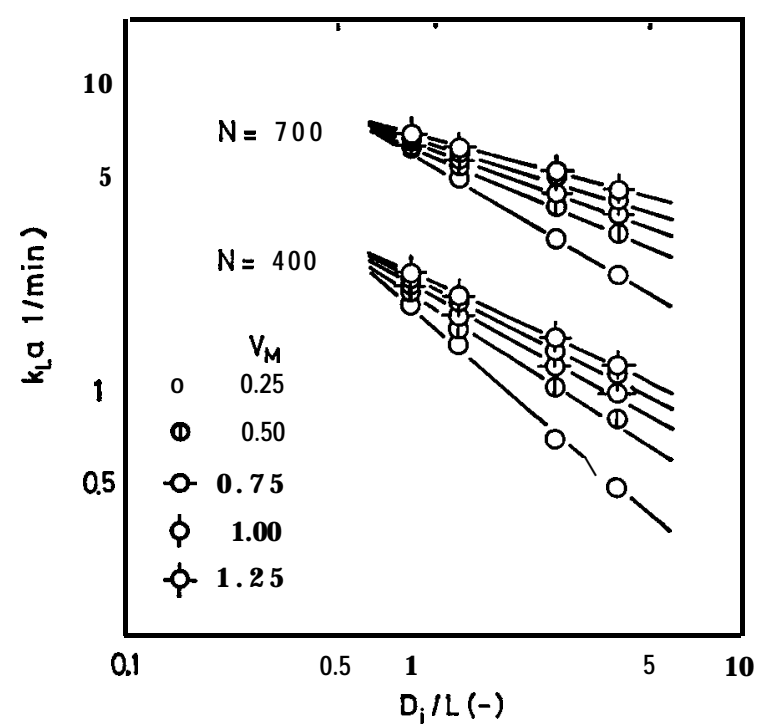

Fig. 7 Correlations between $D_{i} / L$ and $k_{L} a$ with parameters of rotational rates.

$N_{A}$. The term $N_{A}$ in Eq. (2) can be replaced by a modified aeration number, $\left(N_{A} / V^{*}\right)$. Thus, Eq. (3) is obtained.

$$
\left(\frac{k_{L} a}{V_{M}}\right) \propto \alpha\left(\frac{D_{i}}{L}\right) \cdot\left(\frac{N_{A}}{V^{*}}\right)^{\mathrm{b}^{\prime}} \cdot\left(V^{*}\right)^{\mathrm{c}}
$$

From experimental data analysis was carried out to estimate the numerical 


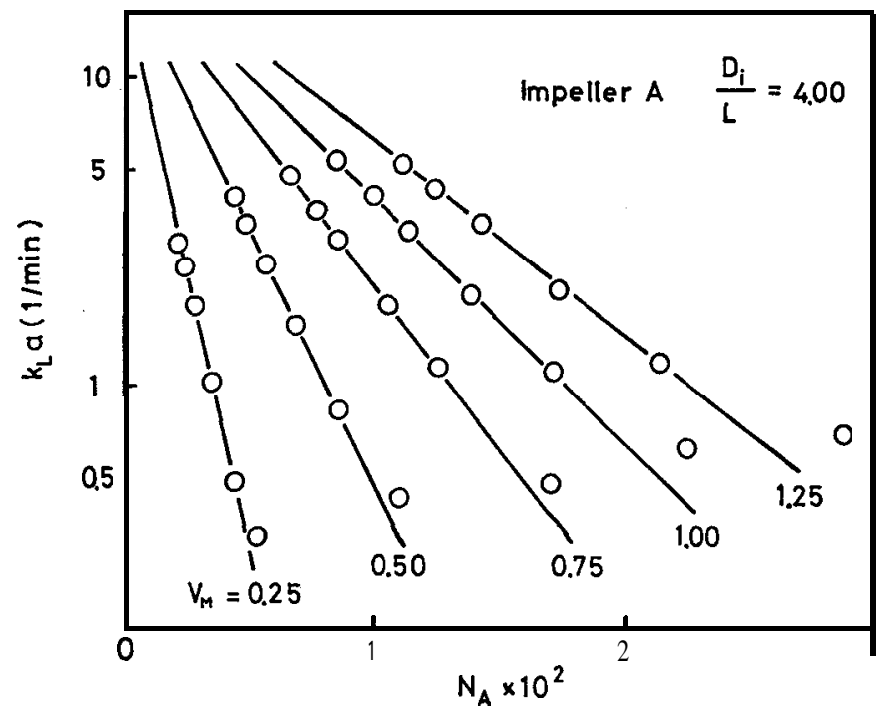

Fig. 8. Logarithmic relationship between $N_{A}$ and $k_{L} a$.

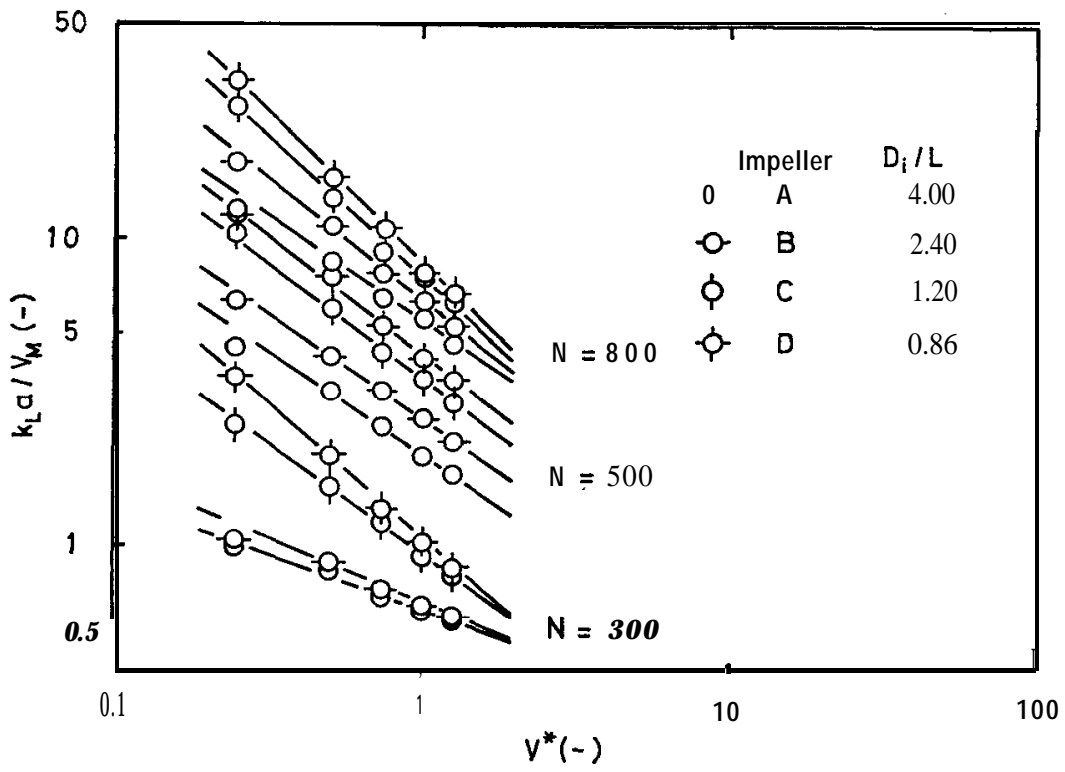

Fig. 9. Decision of numerical value of power, "c" in Eq. (3).

values of powers in Eq. (3). At first,the numerical value of "c" in Eq. (3) could be decided from Fig. 9. In Fig. 9, the slopes in the cases of 300 and $800 \mathrm{rpm}$ differed from the others, but the others (400,600 and $700 \mathrm{rpm})$ showed nearly the same slopes as the case of $500 \mathrm{rpm}$ in Fig. 9. The average numerical value of these slopes was calculated as -0.58 , which is equal to "c." Numerical 


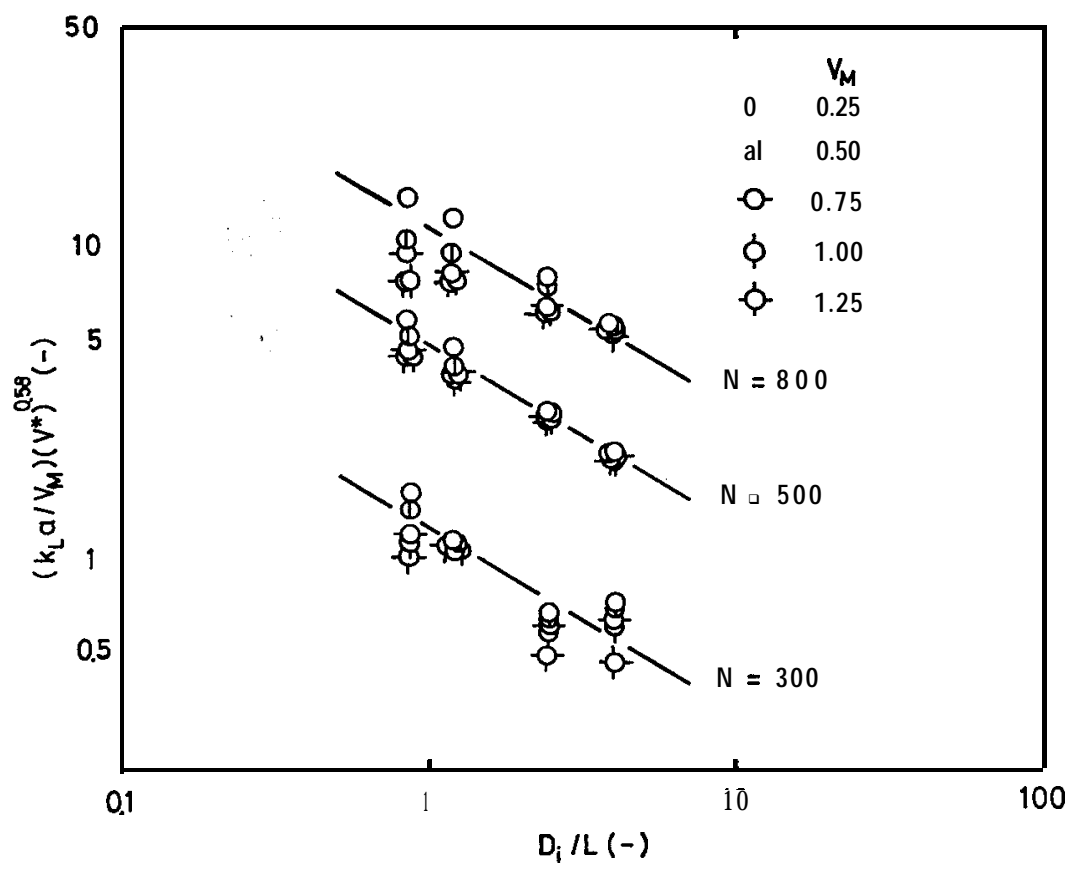

Fig. 10. Decision of numerical value of power, "a" in Eq. (3).

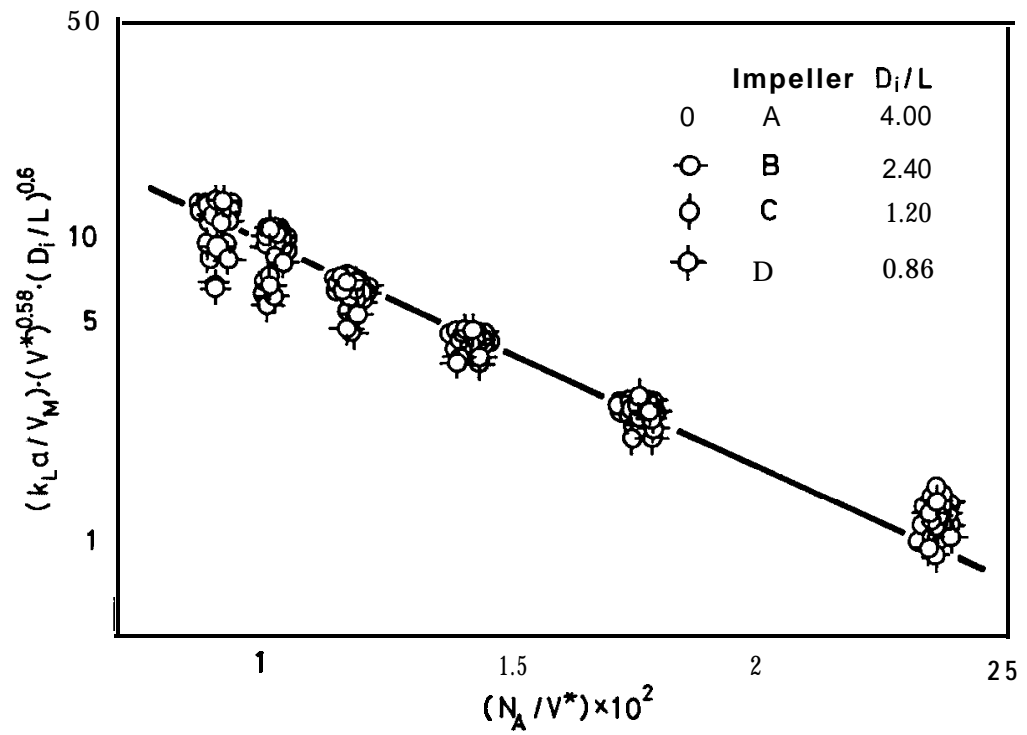

Fig. 11. Correlation between experimental data and Eq. (3) with powers of a=-0.60, $\mathbf{b}^{\prime}=1.00$ and $\mathbf{c}=-0.58$. 
values of "a" could be decided by substituting -0.58 as "c" in Eq.(3). The numerical value of "a" could then be obtained by plotting of $\ln \left(k_{L} a / V_{H}\right) \cdot\left(V^{*}\right)^{0.58}$ against $\ln \left(D_{i} / L\right)$. Thus, the numerical value of "a" was found to be equal to -0.60 , as shown in Fig. 10. To treat $\left(N_{A} / V^{*}\right)$ independently from effects of other factors, there must be plotted the relationship between logarithms of $\left(k_{L} a / V_{H}\right) \cdot\left(V^{*}\right)^{0.58}\left(D_{i} / L\right)^{0.60}$ and $\left(N_{A} / V^{*}\right)^{\mathrm{b}}$. If 1.00 was adopted as the numerical value of " $\mathrm{b}$ '," the result shown in Fig. 11 was obtained. In Fig. 11, there are some deviations at extreme experimental conditions, but it seems to be in good agreement with theoretical analysis to consider that the numerical value of " $\mathrm{b}^{\prime}$ " is equal to 1.00 generally. By substituting numerical values of "a," "b" and "c" into Eq. (3), Eq. (4) results :

$$
\left(\begin{array}{c}
k_{L} a \\
-V_{M}
\end{array}\right) \propto \propto \alpha\left(\begin{array}{c}
D_{i} \\
L
\end{array}\right)^{-0.60} \cdot\left(\frac{N_{A}}{V^{*}}\right) \cdot\left(V^{*}\right)^{-0.58}
$$

The function of Eq. (4) must have the following form, Eq. (5), since $\left(N_{A} / V^{*}\right)$ depends on logarithm of $\left(k_{L} \mathrm{a} / V_{M}\right) \cdot\left(V^{*}\right)^{0.58} \cdot\left(D_{i} / L\right)^{0.60}$.

$$
\ln \left(\left(\frac{k_{L} a}{V_{M}^{-}}\right) \cdot\left(\frac{D_{i}}{L}\right)^{0.60} \cdot\left(V^{*}\right)^{0.58}\right)=\alpha \cdot\left(\frac{N_{A}}{V^{*}}\right)
$$

In these experiments, the slope, a was calculated to be $1.80 \times 10^{-2}$. However, the slope, a in Eq. (5) may involve some complex factors, which were not considered at this analysis, and this point may be subject for a future study on agitated vessels with aeration.

\section{CONCLUSIONS}

In agitated vessel with aeration, an improved impeller was designed to obtain a higher volumetric coefficient under the conditions of a lower rotational rate of impeller and a lower aeration rate. The higher efficiency was obtained by using an improved impeller in comparison with usual flat turbine.

The effect of width of blade of impeller on volumetric coefficient was found to be that $\left(k_{L} a / V_{M}\right)$ was in proportion to $\left(D_{i} / L\right)^{-0.60}$. A quantitative relationship shown in Eq. (5) could be found by using some dimensionless groups involving a modified aeration number.

\section{NOMENCLATURES}

$\begin{array}{lll}C_{0} & \text { dissolved oxygen concentration } & (\mathrm{ppm}) \\ C_{0}^{*} & \text { saturated dissolved oxygen concentration } & (\mathrm{ppm}) \\ D_{i} & \text { diameter of impeller } & (\mathrm{mm}) \\ D_{T} & \text { diameter of vessel } & (\mathrm{mm}) \\ H & \text { hight of vessel } & (\mathrm{mm}) \\ H_{L} & \text { depth of water in vessel } & (\mathrm{mm}) \\ k_{L} a & \text { volumetric coefficient } & (\mathrm{l} / \mathrm{min}) \\ k_{L} a_{A} & \text { volumetric coefficient for impeller A } & (\mathrm{l} / \mathrm{min}) \\ \boldsymbol{L} & \text { width of impeller } & (\mathrm{mm})\end{array}$




$\begin{array}{lll}\mathbf{N} & \text { rotational rate of impeller } & (\mathrm{rpm}) \\ N_{A} & \text { aeration number }:=q_{A} / N \times D_{i}^{3} & (-) \\ q_{A} & \text { gas flow rate } & (\mathrm{ml} / \mathrm{min}) \\ t & \text { time } & (\mathrm{min}) \\ V_{M} & \text { gas volumetric flow rate per unit liquid volume } & (\mathrm{vvm} \text { or } l / \mathrm{min}) \\ V^{*} & \text { dimentionless volumetric gas flow rate ; } & \\ & \text { ratio } V_{M} \text { to } V_{M} \text { equal to 1.00 } & (-) \\ W_{b} & \text { width of baffle } & (\mathrm{mm}) \\ W_{i} & \text { length of impeller blade } & (\mathrm{mm}) \\ \alpha & \text { a proportional coefficient of Eq. (2) } & (-)\end{array}$

\section{REFERENCES}

Calderbank, P. H. 1958 The interfacial area in gas-liquid contacting with mechanical agitation. Trans. Instn. Chem. Engrs., 36: 443-463

Cooper, C.M., G. A. Fernstrom and S. A. Miller 1944 Performance of agitated gas-liquid contactors. Ind. Eng. Chem., 36: 504-509

Kamei, S., S. Nagata and N. Yoshioka 1949 Studies on the power requirements for paddle agitators in cylindrical vessels. Kagaku Kikai,13: $\mathbf{3 5 - 4 0}$

Mizushina, T., R. Ito, S. Hiraoka, M. Tanaka and K. Fujimoto 1971 Flow patterns in agitated vessels with paddle type impellers. J. Chem. Eng. Japan, 35: 471-477

Ohyama, Y. and K. Endoh 1955 Power characteristics of gas-liquid contacting mixers. J. Chem. Eng. Japan, 19: 2-8

Steel, R. and M. R. Brierley 1958 Agitation-aeration in submerged fermentation. App. Microbiol., 7: 51-56 